\title{
STATISTICAL SURVEY OF THE PATHOLOGY, DIAGNOSIS AND REHABILITATION OF ETICS IN WALLS
}

\author{
Bárbara AMARO, Diogo SARAIVA, Jorge de BRITO, Inês FLORES-COLEN \\ Department of Civil Engineering, Architecture and Georesources, Instituto Superior Técnico, \\ Technical University of Lisbon, Av. Rovisco Pais, 1049-001 Lisbon, Portugal
}

Received 17 April 2012; accepted 25 May 2012

\begin{abstract}
This paper presents a statistical survey on the pathology, diagnosis and rehabilitation of ETICS (external thermal insulation composite system) in walls. The development of an expert-knowledge inspection and diagnosis system for this type of cladding implied the creation of classification lists of anomalies, most probable causes, diagnosis methods and repair/maintenance techniques. The collection of data through field work where the tools developed within the proposed system were applied was the basis for this statistical survey. The field work consisted of the visual inspection of 146 façades with ETICS cladding located in various areas in Portugal and aged from 3 to 22 years. The data obtained enable anomalies to be related to their causes and so conclusions can be drawn on the best way to minimize the development of the former and eliminate the latter, at the design and application stages. The study further revealed the main sensitive issues of the cladding system during its service life, highlighting the importance of a correct maintenance plan.
\end{abstract}

Keywords: inspection and diagnosis system, ETICS, anomalies, causes, repair, statistical analysis.

Reference to this paper should be made as follows: Amaro, B.; Saraiva, D.; de Brito, J.; Flores-Colen, I. 2014. Statistical survey of the pathology, diagnosis and rehabilitation of ETICS in walls, Journal of Civil Engineering and Management 20(4): 511-526. http://dx.doi.org/10.3846/13923730.2013.801923

\section{Introduction}

Besides being an innovative system, ETICS (external thermal insulation composite system) constitutes an excellent solution from the energy and constructive points of view for the rehabilitation of buildings with insufficient thermal insulation, leakage problems or degraded aspect. Initially this system was used almost exclusively in services buildings but as its market importance grew the price fell to the point when it became common in residential buildings. Over time the system was used widely in Portugal, as reflected in an increase in the area of cladding installed (Fig. 1) (Duarte 2011). Relative to other countries in Europe the application of ETICS (in relative area) in Portugal is still very small, as seen in Figure 2 (Duarte 2011). The components of this insulation system may vary and they are chosen according to the level of insulation, mechanical resistance and surface finishing required. Presently much of the energy from heating systems is wasted by leakage through passages that can easily be insulated, and it is therefore crucial that thermal insulation is installed to reduce such waste. The integrity and proper performance of insulation is fundamental to its efficiency, which leads to the issue of its inspection, maintenance and preservation.

The main problem with ETICS is that they are still a relatively modern solution where long-term experience has not been gathered and published. The relevance of this problem is illustrated by the potential impacts of ETICS in buildings: positive impacts in energy savings and improvement of the thermal comfort; negative impacts in terms of unfulfilled expectations in terms of efficiency, architectural integration and durability. This paper focuses especially in this last aspect.

The aim of this research is to implement a methodology for the inspection, diagnosis and repair of ETICS to monitor their performance in walls. The system was validated through the inspection of a sample of 146 façades (14 buildings/sets of buildings) where various anomalies were observed, causes identified, in situ diagnosis tests recommended and repair techniques proposed, all designed to eliminate the root causes of pathologies.

The pathological survey of ETICS has been studied elsewhere with a view to analysing their applicability in new and rehabilitated construction (Duarte et al. 2011; Fernandes, de Brito 2012; Freitas 2002) and evaluating their degradation (Barreira, Freitas 2008; Künzel et al. 2006; Stazi et al. 2009; Daniotti, Paolini 2008).

The whole expert system is described in detail in another paper by the same authors (Amaro et al. 2013) and is included in a series of works (classification lists and correlation matrices) based on initial research by de Brito (2009). This methodology has thus been tested and implemented in various cladding systems/construction elements (Silvestre, de Brito 2009; Pereira et al. 2011; Neto, de Brito 2011; Sá et al. 2011). 


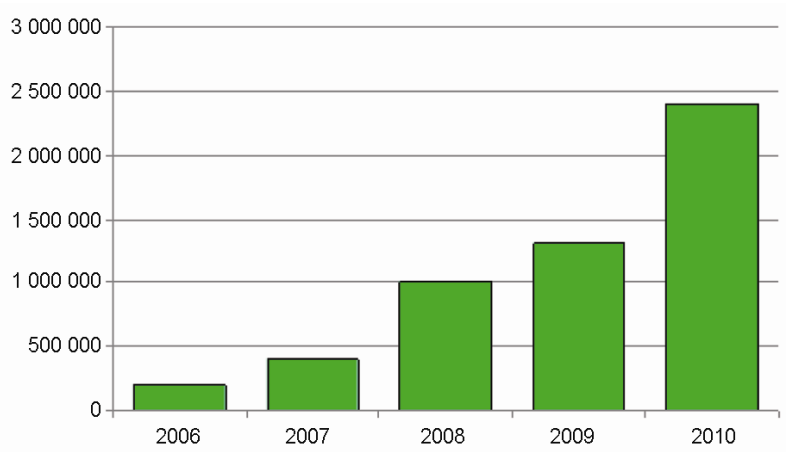

Fig. 1. Evolution of the application of ETICS (in $\mathrm{m}^{2}$ ) in Portugal (Duarte 2011)

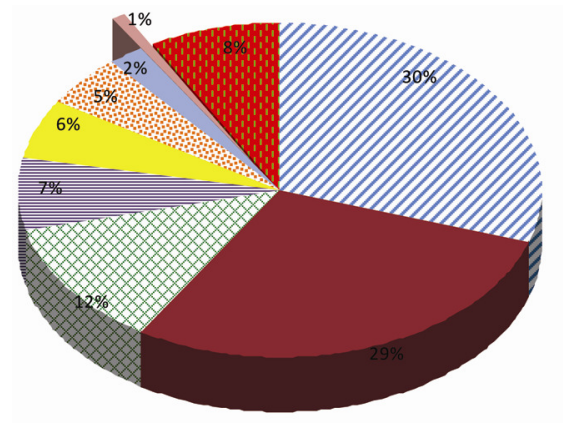

$$
\begin{aligned}
& \text { " Germany } \\
& \text { - Poland } \\
& \text { x Czech Republic } \\
& \equiv \text { Italy } \\
& \text { - Austria } \\
& \text { iz. Slovakia } \\
& \text { In France } \\
& \text { n- Portugal } \\
& \text { a Others }
\end{aligned}
$$

Fig. 2. Application of ETICS (in relative area) in Europe in 2008 (Duarte 2011)

Besides the proposed innovative expert-knowledge management system specifically tailored for ETICS in walls, this paper presents the statistical evaluation of the results of an inspection program of ETICS, that is unprecedented in the literature in terms of size of the sample analysed, scope of the analysis (pathology, diagnosis and rehabilitation) and systemic approach to data collection and analysis. It provides valuable information to building authorities, designers, contractors, owners and maintenance/rehabilitation management firms.

\section{Sample characterisation}

The field work was done between April and June 2011 and data was collected by visual inspection to validate the expert knowledge-based tools used to detect any pathology in, and implement a diagnosis and repair system on ETICS. It was initially based on a literature review. The sample consisted of 14 buildings/sets of buildings comprising 146 façades coated with ETICS aged from 3 to 22 years, in which 476 anomalies were registered. 1098 causes (518 indirect and 580 direct) were associated with these anomalies, and 662 auxiliary diagnosis methods and 768 repair techniques were recommended. Table 1 shows the most important characteristics of each building/set of buildings inspected.

\subsection{Geographical distribution of the sample}

The buildings inspected covered a good part of the Portuguese territory, particularly the north and centre regions (Fig. 3). Since ETICS were most frequently used in Portugal to comply with buildings' thermal comfort regula- tions, this system is mostly found in the north, where it is cooler. That is why more buildings were inspected in Porto, approximately $19400 \mathrm{~m}^{2}$ of façade area, around the same as the total façade area inspected in the centre of the country $\left(5250 \mathrm{~m}^{2}\right.$ in Coimbra and $11780 \mathrm{~m}^{2}$ in Lisbon Metropolitan Area). No buildings in the south were inspected since there are far fewer buildings with ETICS there and the few there are, are relatively recent.

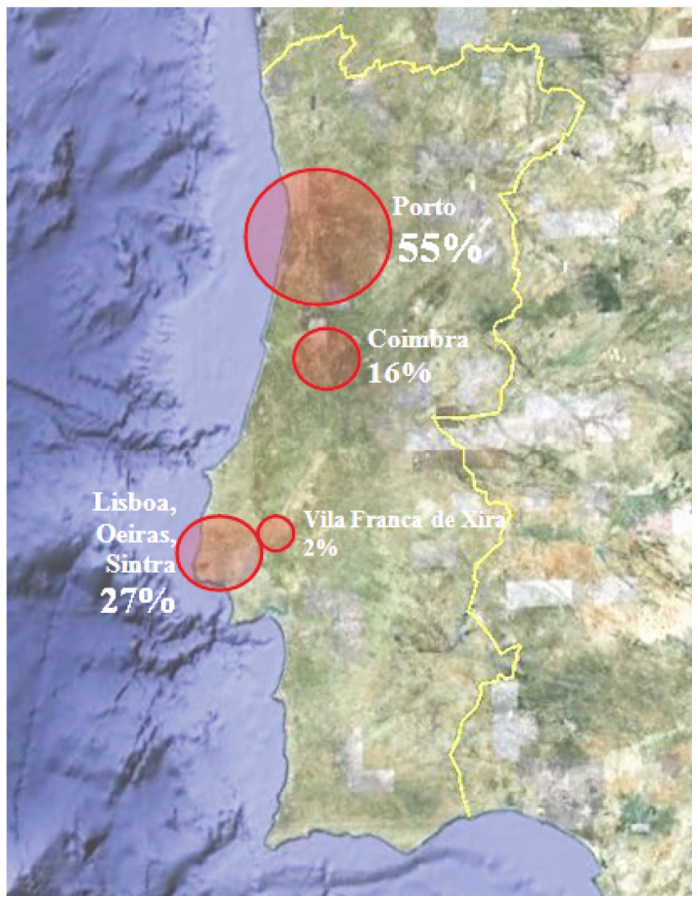

Fig. 3. Geographical distribution of the sample

\subsection{Age distribution of the sample}

ETICS are a relatively novel technology in the Portuguese construction sector, having only really expanded in the 1990s. The 146 façades inspected comprise ETICS applied between 1989 and 2008, thus the data collected had a considerable range of parameters. Considering that the validation of the inspection and diagnosis system should focus on the oldest possible ETICS to show their pathology, 20 façades over 20 years old were inspected, plus 84 between 10 and 20 years old and 42 less than 10 years old. Figure 4 shows the number of façades inspected by age of application of the system, giving an average of 13 years.

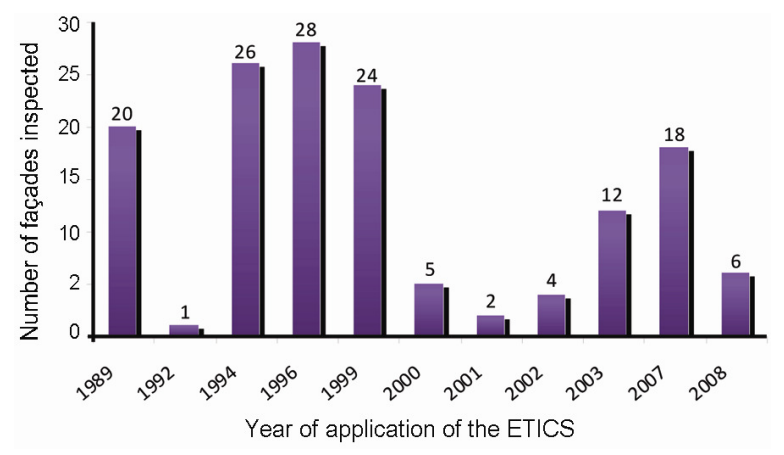

Fig. 4. Age distribution of the sample 


\section{Inspection and diagnosis}

The inspection plan used to identify and characterise the anomalies observed and define their origin is presented here. The inspection and validation files used are also presented.

\subsection{Inspection plan}

Inspections are generally classified according to their periodicity and they are often designated as current, detailed and structural/functional evaluation (Table 2). However, in this case the main objective of the inspections was to validate the classification lists and correlation matrices within the expert system.
The inspection plan consisted of a set of visits to inspect façades with ETICS cladding and use visual criteria to identify the anomalies and their most probable causes. Auxiliary diagnosis methods are mentioned only as a recommendation since, for economy reasons, no tests were actually performed. The anomalies were mapped to identify their location and so make it easier to monitor them in post-inspection interventions.

The repair actions were prioritised on the basis of availability of funding and thus privileged the more serious anomalies, according to the quality criteria requirements. After any intervention a pro-active (predictive) monitoring plan of premature degradation or re-pathology must be kept up.

Table 1. Main characteristics of the buildings inspected in the field work

\begin{tabular}{|c|c|c|c|c|c|}
\hline & Type of use & $\begin{array}{c}\text { Year of } \\
\text { application }\end{array}$ & $\begin{array}{l}\text { No. of } \\
\text { façades }\end{array}$ & Characterization of the surroundings & $\begin{array}{l}\text { Area } \\
\left(\mathrm{m}^{2}\right)\end{array}$ \\
\hline \multicolumn{6}{|c|}{ Ed 1 - Bairro Alto da Eira } \\
\hline $\begin{array}{l}\text { St. Mouzinho de } \\
\text { Albuquerque, Lisbon }\end{array}$ & Housing & 2003 & 12 & $\begin{array}{l}\text { Social neighbourhood with some propensity to } \\
\text { vandalism }\end{array}$ & 6080 \\
\hline \multicolumn{6}{|c|}{ Ed 2 - Tagus Park - Siza Vieira } \\
\hline Tagus Park, Oeiras & Offices & 2008 & 6 & Detached office building in the Tagus Park complex & 2750 \\
\hline \multicolumn{6}{|c|}{ Ed 3 - Housing cooperative of Massarelos } \\
\hline $\begin{array}{l}\text { Housing cooperative of } \\
\text { Massarelos, St. de Salgueiro } \\
\text { Maia, Porto }\end{array}$ & Housing & 1994 & 16 & Housing neighbourhood in a very busy urban area & 4350 \\
\hline \multicolumn{6}{|c|}{ Ed 4 - FAUP } \\
\hline $\begin{array}{l}\text { FAUP, Via Panorâmica } \\
\text { Porto }\end{array}$ & Services & 1989 & 20 & $\begin{array}{l}\text { University complex in an urban surrounding, with } \\
\text { considerable number of trees around it }\end{array}$ & 2700 \\
\hline \multicolumn{6}{|c|}{ Ed 5 - Outeiro neighbourhood } \\
\hline $\begin{array}{l}\text { Bairro do Outeiro/St. do } \\
\text { Mondego, Porto }\end{array}$ & Housing & 2007 & 15 & Housing neighbourhood in a very busy urban area & 4200 \\
\hline \multicolumn{6}{|c|}{ Ed 6 - FEUP - Departments of Engineering } \\
\hline $\begin{array}{l}\text { FEUP, St. Dr. Plácido da } \\
\text { Costa 91, Porto }\end{array}$ & Services & 1999 & 24 & $\begin{array}{l}\text { University complex in an urban surrounding, with } \\
\text { considerable movement of people and vehicles }\end{array}$ & 6250 \\
\hline \multicolumn{6}{|c|}{ Ed 7 - FEUP - Canteen } \\
\hline $\begin{array}{l}\text { FEUP, St. Dr. Plácido da } \\
\text { Costa, Porto }\end{array}$ & Services & 2001 & 2 & $\begin{array}{l}\text { Canteen of FEUP, protected from direct human } \\
\text { contact. Façades inspected exposed to a watering } \\
\text { system }\end{array}$ & 150 \\
\hline \multicolumn{6}{|c|}{ Ed 8 - FEUP - INESC } \\
\hline $\begin{array}{l}\text { FEUP - IESCP, St. Dr. } \\
\text { Roberto Frias, Porto }\end{array}$ & Services & 2002 & 4 & $\begin{array}{l}\text { Detached building with major vegetation near one of } \\
\text { the façades }\end{array}$ & 1750 \\
\hline \multicolumn{6}{|c|}{ Ed 9-FCTUC - Department of Informatics Engineering } \\
\hline $\begin{array}{l}\text { FCTUC, Pólo II, St. Sílvio } \\
\text { Lima, Coimbra }\end{array}$ & Services & 1994 & 10 & $\begin{array}{l}\text { University complex in a rural surrounding with } \\
\text { considerable number of trees around it }\end{array}$ & 2850 \\
\hline \multicolumn{6}{|c|}{ Ed 10 - FCTUC - Department of Civil Engineering } \\
\hline $\begin{array}{l}\text { FCTUC, Pólo II, St. Sílvio } \\
\text { Lima, Coimbra }\end{array}$ & Services & 2000 & 5 & $\begin{array}{l}\text { University complex in a rural surrounding with } \\
\text { considerable number of trees around it and some } \\
\text { movement of people and vehicles }\end{array}$ & 650 \\
\hline \multicolumn{6}{|c|}{ Ed 11 - FCTUC - Department of Electrical and Computers Engineering } \\
\hline $\begin{array}{l}\text { FCTUC, Pólo II, St. Sílvio } \\
\text { Lima, Coimbra }\end{array}$ & Services & 1996 & 9 & $\begin{array}{l}\text { University complex in a rural surrounding with } \\
\text { considerable number of trees around it }\end{array}$ & 1750 \\
\hline \multicolumn{6}{|c|}{ Ed 12 - Hotel IBIS } \\
\hline Av. José Malhoa, Lisbon & Services & 2002 & 1 & Hotel in Lisbon in a street with considerable traffic & 1000 \\
\hline \multicolumn{6}{|c|}{ Ed 13 - Museum of Neo-realism } \\
\hline $\begin{array}{l}\text { St. Alves Redol, Vila Franca } \\
\text { de Xira }\end{array}$ & Services & 2007 & 3 & $\begin{array}{l}\text { Museum in Vila Franca de Xira in an urban area } \\
\text { with considerable car traffic }\end{array}$ & 700 \\
\hline \multicolumn{6}{|c|}{ Ed 14 - Urbanization Quinta Verde } \\
\hline $\begin{array}{l}\text { Quinta Verde, São Martinho, } \\
\text { Massarelos, Sintra }\end{array}$ & Housing & 1996 & 19 & $\begin{array}{l}\text { Urban development of houses in a rural area with a } \\
\text { lot of trees }\end{array}$ & 1250 \\
\hline
\end{tabular}


Table 2. Characterisation of the types of inspection plans

\begin{tabular}{|c|c|c|c|c|}
\hline $\begin{array}{l}\text { Type of } \\
\text { inspection }\end{array}$ & Periodicity & $\begin{array}{l}\text { Minimum/maximum } \\
\text { periodicity }\end{array}$ & Objective & Method \\
\hline Current & \multirow[b]{2}{*}{ Periodic } & 12 to 24 months & $\begin{array}{l}\text { Detect fast-developing anomalies, } \\
\text { monitor anomalies detected in previ- } \\
\text { ous inspections }\end{array}$ & $\begin{array}{l}\text { Visual observation of ETICS; little } \\
\text { equipment needed }\end{array}$ \\
\hline Detailed & & 5 to 10 years & $\begin{array}{l}\text { Monitor anomalies detected in previ- } \\
\text { ous inspections, determine their ex- } \\
\text { tent, severity and causes }\end{array}$ & $\begin{array}{l}\text { Visual observation, non- } \\
\text { destructive in situ tests, considera- } \\
\text { ble backing in terms of personnel } \\
\text { and material }\end{array}$ \\
\hline $\begin{array}{c}\text { Post- } \\
\text { intervention }\end{array}$ & Non-periodic & - & $\begin{array}{l}\text { Verify early degradation due to appli- } \\
\text { cation errors of the repair techniques }\end{array}$ & $\begin{array}{l}\text { Visual observation of ETICS; } \\
\text { reduced need of equipment }\end{array}$ \\
\hline
\end{tabular}

Table 3. Standard inspection file



\subsection{Inspection files}

The inspection files' main function was to characterise the inspected building and its façades. One inspection file was sometimes created for a set of buildings where the individual buildings all had the same characteristics and had been built in the same period, as in some neighbourhoods or university campuses.

The information in the inspection files may help to characterise the anomalies or to identify causes. Some- times difficulties in accessing the original design and reports from previous interventions may prevent all the information needed from being obtained. Table 3 shows a standard inspection file before it is filled in on site.

\subsection{Validation files}

The validation files complement the inspection files and register for each façade the anomalies and their characteristics, the most probable causes, the diagnosis methods 
and the repair techniques considered most appropriate, in order to validate the expert system proposed. Table 4 gives a standard validation file before it is filled in on site.

\section{Statistical analysis}

Based on the data collected by visual inspection when the system is validated, a statistical analysis of the pathologi- cal phenomena that occur in ETICS insulation systems was performed to enable assessment of the parameters the system is most sensitive to, in order to minimise the degradation process. The analysis followed the approach used for other construction elements, such as ceramic tiles, natural stone cladding and renderings (Silvestre, de Brito 2011; Neto, de Brito 2012; Sá et al. 2011).

Table 4. Standard validation file

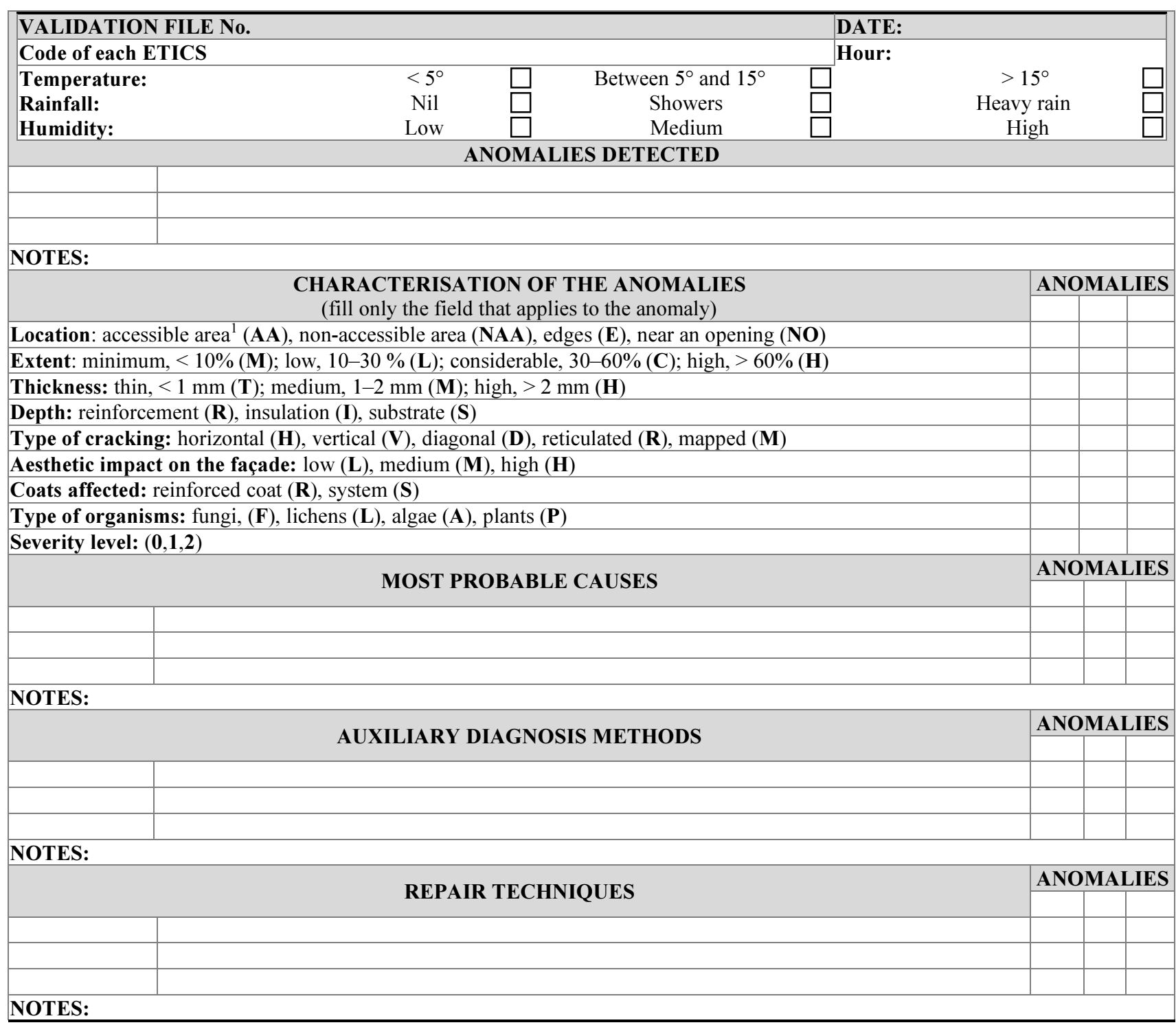

\subsection{Incidence of the anomalies}

The data for this section is represented graphically in Figures 5, 6 and 7, which cope with the contribution of each anomaly and group of anomalies within the sample.

Figures 5 and 6 indicate that the commonest anomalies are A-C5 - Biological growth (present on 55.5\% of the façades inspected), A-C6 - Other colour changes (48.6\%) and A-C2 - Runoff marks (43.2\%). All three commonest anomalies belong to group A-C - Colour/Aesthetic anomalies, which is not usually associated with dire consequences in terms of thermal capacity.

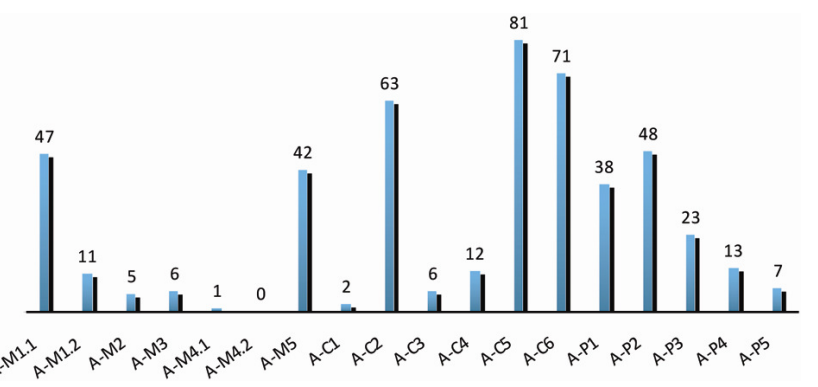

Fig. 5. Anomalies within the sample 


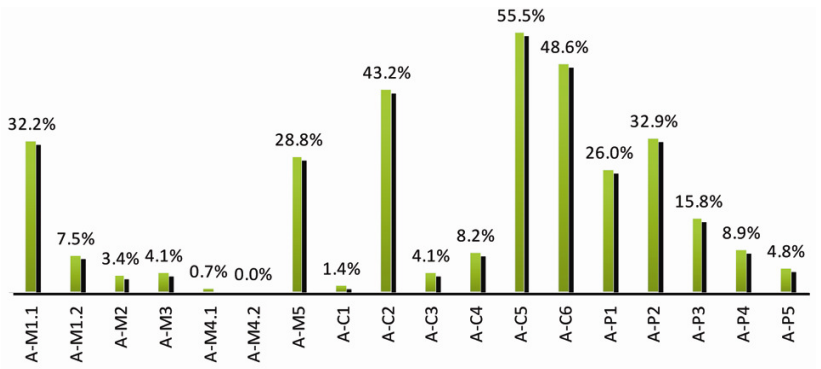

Fig. 6. Incidence of the anomalies in terms of probability of occurring in a façade

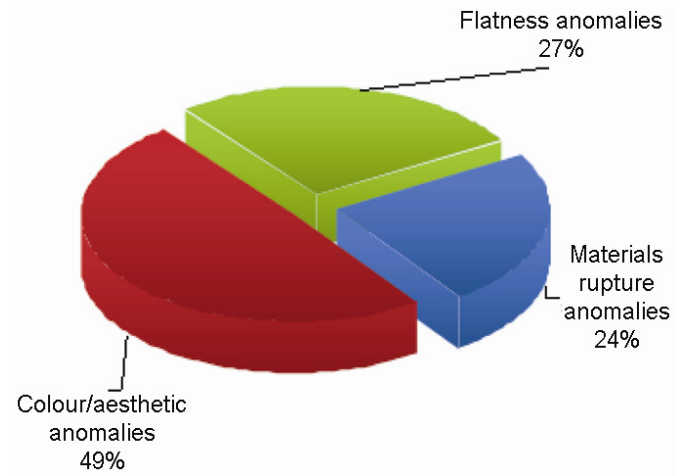

Fig. 7. Contribution of each anomaly group to the grand total of anomalies detected

This is why this group of anomalies has a higher incidence relative to the other groups, as seen in Figure 7.

Another paper on Portuguese ETICS (Silva, Falorca 2009) corroborates these results for the prevalence of colour changes over other anomalies. In fact various authors (Barreira et al. 2013; Flores-Colen et al. 2008; Künzel 1998) have studied the development of stains, especially those associated with surface condensation, to try and scientifically explain their occurrence and also minimise them. Other anomalies related to wall colour occur significantly less often than those mentioned above, e.g. 8.2\% for A-C4 - Graffiti, half the incidence of corrosion stains (A-C3) and next to no occurrences of A-C1 - Efflorescence on ETICS (of 146 façades only two showed this anomaly and its extent was considered minimum, i.e. less than $10 \%$ of the façade area).

The graphs further show that group A-M - Materials rupture anomalies is the least frequent in the sample ( $24 \%$ of the total). No case of loss of adherence of the whole system and only one of partial adherence loss were detected in the sample (anomalies A-M4.2 and A-M4.1, respectively). This is a positive finding since these anomalies represent the worst scenarios of ETICS' defects and have very severe consequences for the thermal behaviour of the building. However, according to French statistics based on insurance companies' reports relative to 211 anomaly examples in ETICS between 1979 and 1985 (Freitas 2002), the incidence of loss of adherence of the whole system was $12 \%$ and of partial adherence loss was also $12 \%$, indicating much higher incidence than found in this study, even though the French study is much older (ETICS' reliability has improved over the years). It is concluded that the non-observance of loss of adherence of ETICS in this field work is linked to the implicit need of immediate corrective intervention, and so these occurrences are hidden from random inspections such as those in this work (as opposed to those that involve insurance companies that are usually expensive and extensive). The materials rupture anomalies is generally the group with the greatest probability of causing changes that hinder the normal performance of the system. Therefore the incidence found for cracking (39.7\% of the sum of A-M1.1 Oriented cracking and A-M1.2 - Non-oriented cracking), and for -M5 - Material gap (28.8\%), may be considered worrying. However, based on the characterisation of anomalies undertaken during the field work, it was found that most of these anomalies are of minimal extent (crack width less than $1 \mathrm{~mm}$ ) and are therefore relatively easy to solve and do not yet significantly affect the system as a whole.

Still, in the same group anomalies, A-M2 - Deterioration of the covering of reinforcement cantilevers and AM3 - Detachment of the finishing coat are relatively rare in ETICS, with only 5 and 6 occurrences in this sample, which corresponds to incidences of $3.4 \%$ and $4.1 \%$, respectively.

Concerning anomalies visually associated with changes to the flatness of the wall, we can distinguish between those that are not particularly detrimental in terms of the system's thermal performance (A-P1, A-P2 and A-P3), which were registered with the purpose of determining the cause of loss of flatness and homogeneity of the wall, from the swelling anomalies (A-P4 and A-P5) which result from mechanical actions associated with incorrect use of materials or faulty system application. Anomalies A-P1 - Flatness deficiency, A-P2 - Surface irregularities and A-P3 Joints between plates visible were registered 38, 48 and 23 times, respectively, in the sample, indicating a moderate incidence in walls with ETICS. The other flatness anomalies concern swelling of the finishing coat (A-P4) and swelling of the insulation plates (A-P5), whose occurrence has the direst consequences, were observed less frequently ( $8.6 \%$ and $4.8 \%$, respectively). It is concluded from the analysis of these incidences that the anomaly classification list proposed enables a good understanding of the pathologies that affect ETICS.

\subsection{Incidence of the causes}

It was expected that the field work would make it possible to relate each anomaly to its most probable cause(s) by visual inspection, with indexes of 1 or 2 assigned to indirect and direct causes, respectively. 1098 causes were assigned in the whole sample, 518 of which were considered indirect and the rest direct.

The data that relates to the contribution of each cause to all the anomalies observed is found in Figures 8 to 13 , where each figure corresponds to a group of causes. Figure 14 shows the contribution of each group to the set of anomalies in the sample. Figures 15 and 17 represent the contribution of the groups of causes, divided in terms of "initial stages" (design and application), "exposure" (environmental and external mechanical actions) and "others" (the other groups). 

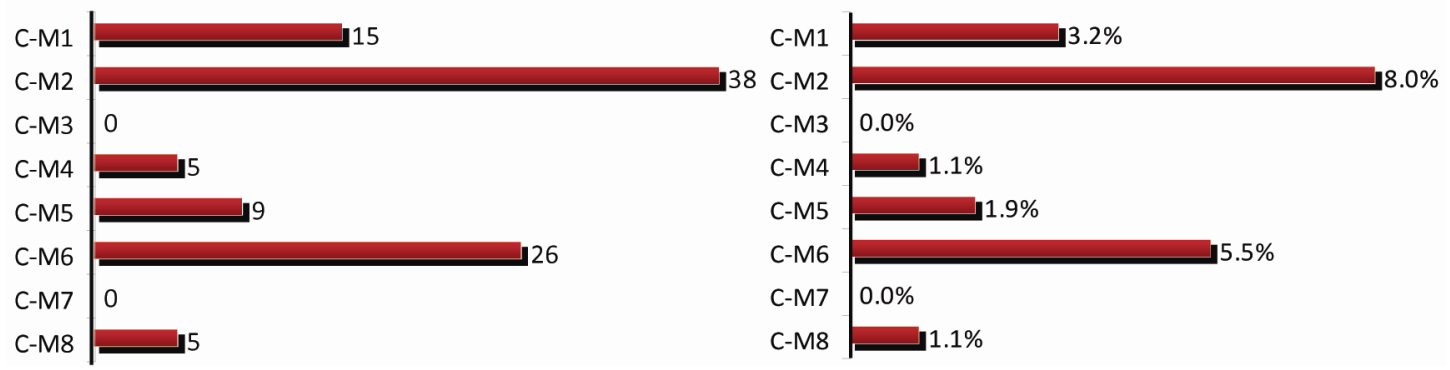

Fig. 8. Absolute and relative incidence of materials selection errors

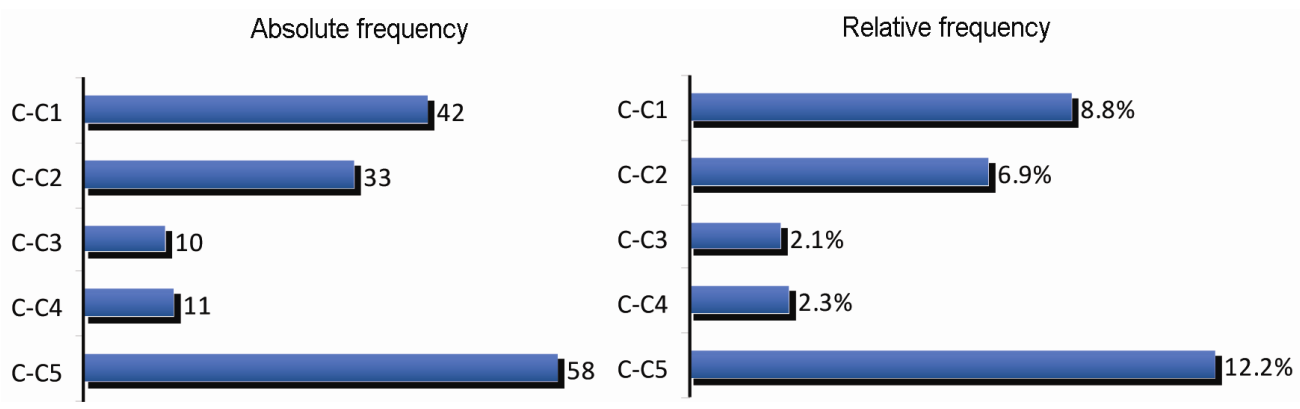

Fig. 9. Absolute and relative incidence of design errors

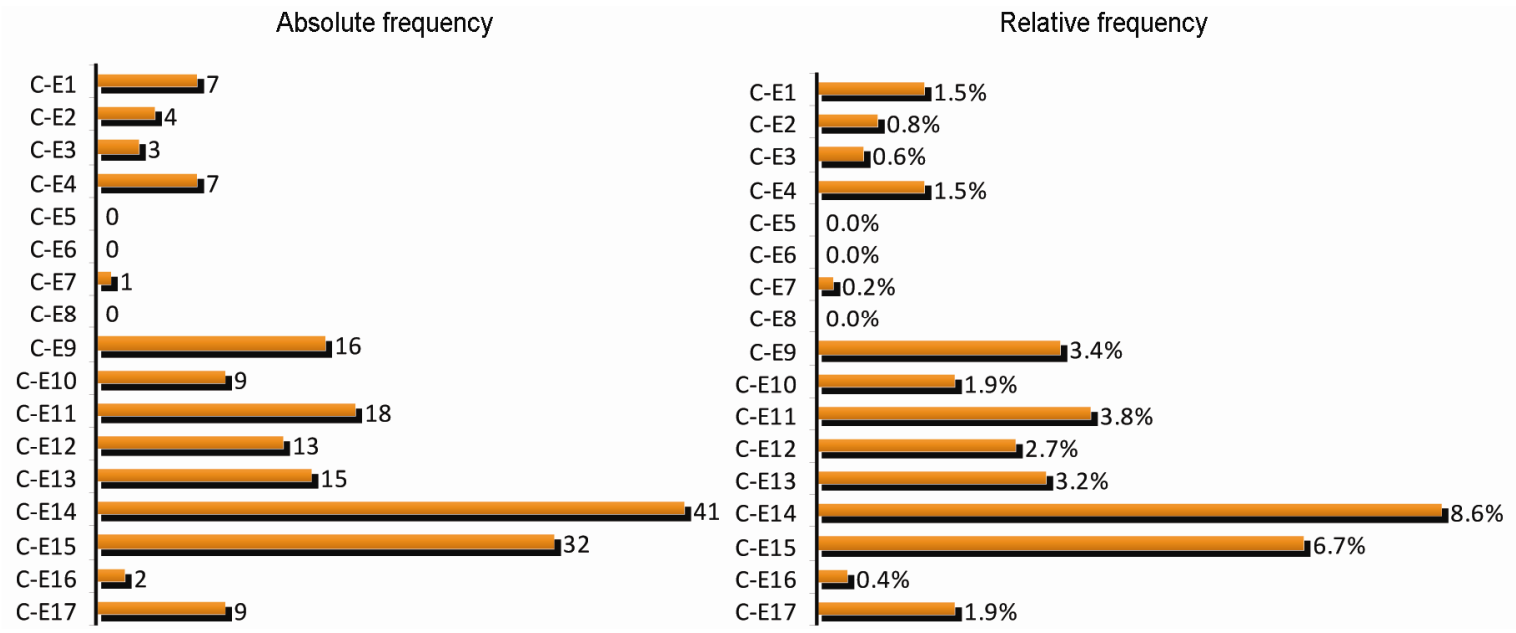

Fig. 10. Absolute and relative incidence of application errors

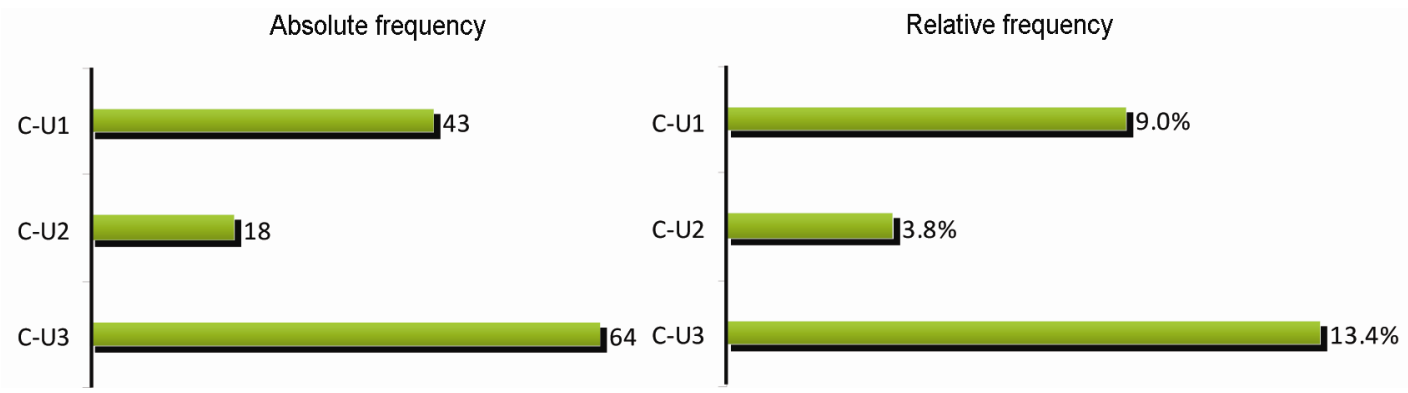

Fig. 11. Absolute and relative incidence of maintenance errors 
Absolute frequency

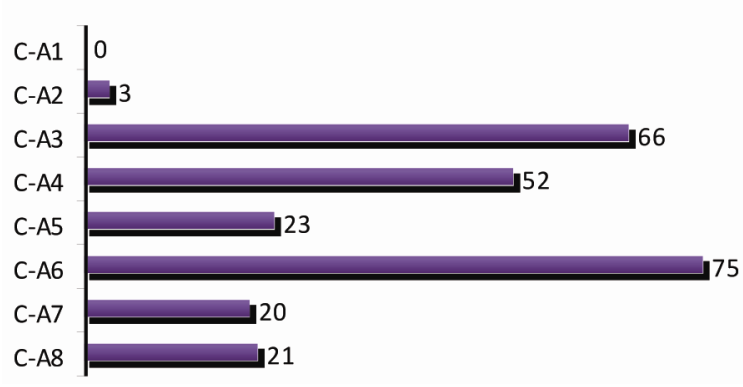

Relative frequency

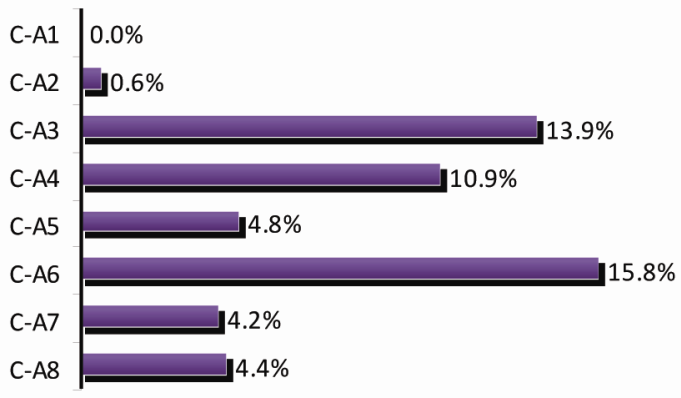

Fig. 12. Absolute and relative incidence of environmental actions

Absolute frequency

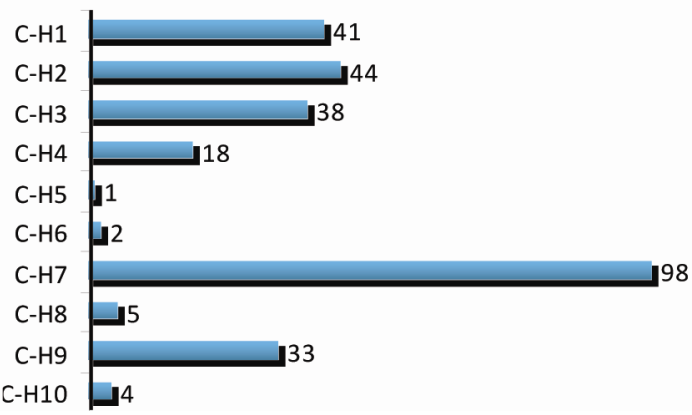

Relative frequency

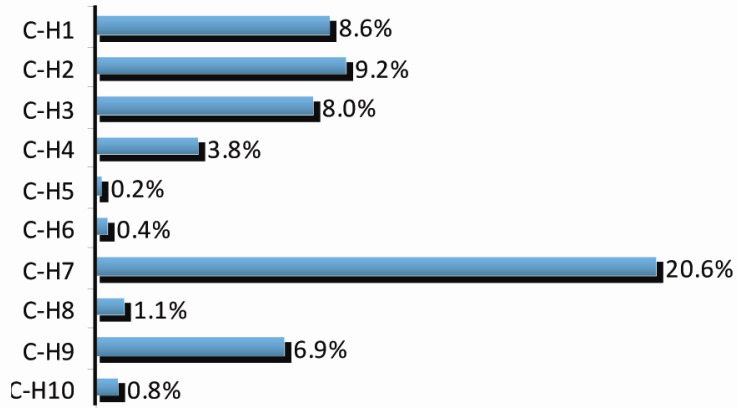

Fig. 13. Absolute and relative incidence of external mechanical actions

The cause considered to be at the root of anomaly development most often was $\mathbf{C}-\mathbf{H 7}$ - Dirt build-up (dust), with a grand total of 98 occurrences. In fact the accumulation of dust particles or pollution can be associated with a variety of factors, including very rough cladding, atmospheric pollution/particles driven by wind/rain, the boundaries between areas of different flatness or any situations resulting from the façades getting wet, and this cause is thus directly or indirectly related to various anomalies.

Causes $\mathbf{C}-\mathbf{H 1}$ and $\mathbf{C}-\mathbf{H 2}$, impacts and perforation of the system respectively, occur 85 times. This is more than all the material gap occurrences (the main consequence of these actions) put together, since they are also associated with anomaly A-P2 - Surface irregularities, which results in several instances of repairing perforations of the system. This reveals one of the sensitive aspects of ETICS, which is their poor surface resistance (in particular to perforations). Also associated with these causes (and anomalies) are design and application errors in which the designers and appliers are held responsible for not strengthening the system properly in areas accessible to the public.

Figure 14 shows that group C-H - External mechanical actions, which includes the causes mentioned, accounts for the greatest proportion of all causes registered with $26 \%$ of the total. Similarly group C-A - Environmental actions represent $24 \%$ of the grand total of causes attributed. The causes within this group can be associated with the climatic conditions during application of the system and with subsequent in-service actions. The first, even though mentioned several times in the literature on this topic (Freitas 2002; Silva, Falorca 2009; Fernandes 2010), are difficult to recognise due to the limitations of visual inspection a long time after the system has been applied. Therefore causes C-A1 - Strong wind when cladding is applied and C-A2 - Exceptionally low temperature during application of the cement-glue or covering have been given incidences of only $0 \%$ and $0.6 \%$, respectively. As for the remaining environmental actions, mostly in the second subgroup, they all occurred at least 20 times, which is why this group of causes makes such a big contribution to ETICS anomalies. In fact the upper left graph of Figure 15 shows that $65 \%$ of the colour anomalies are associated with the exposure of façades to environmental or external mechanical actions, the only group of anomalies that is not primarily influenced by design and application errors. Since this group of anomalies occurs most often in the sample ( $49 \%$ of the total), these two groups of causes together stand out from the others.

In Figure 12 causes C-A6 - Surface condensation damp and $\mathbf{C}-\mathbf{A} \mathbf{3}$ - Rain action stand out, because they come second and third in terms of frequency of attribution in the whole sample. In fact these two causes are directly related to the commonest anomalies since they propitiate the development of micro-organisms, the adhesion of dirt to the wall and the formation of water runoff marks. Another sensitive aspect of this system is thus highlighted - the propensity of the façade to suffer long periods of damp, thus allowing the related anomalies to develop. 


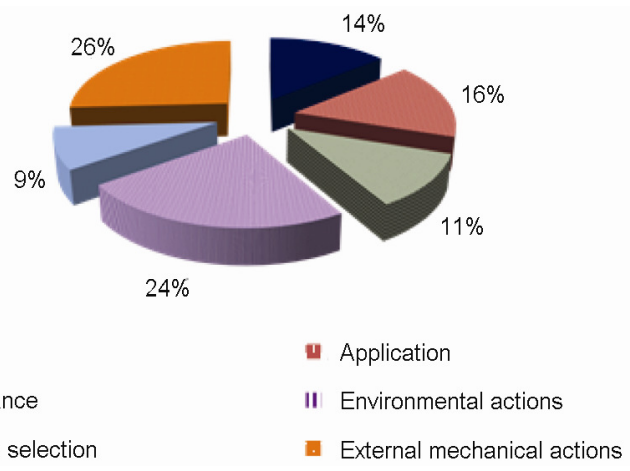

Fig. 14. Contribution of each cause group to the grand total of causes attributed
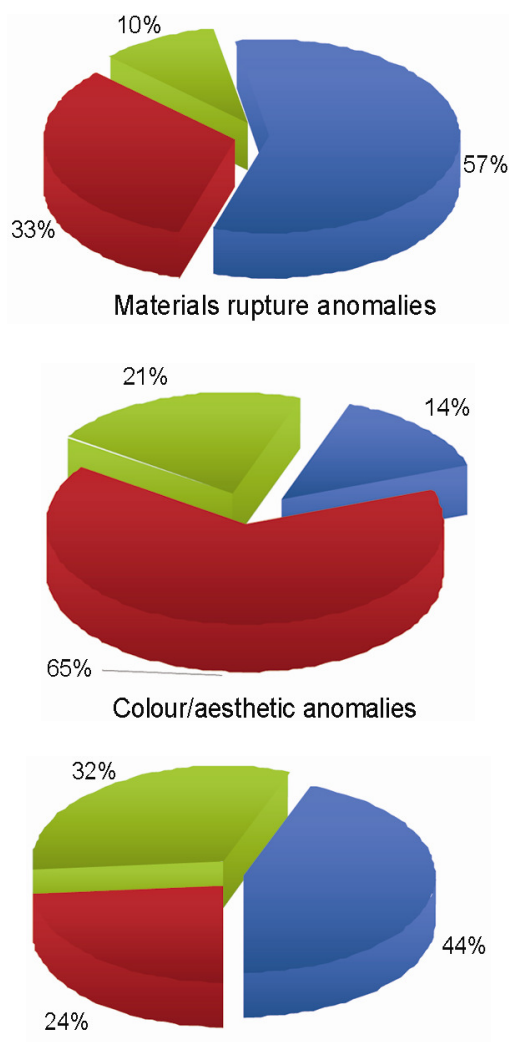

$$
\begin{aligned}
& \text { Flatness anomalies } \\
& \text { Initial stages }(C+E) \\
& \text { Exposure }(A+E) \\
& \text { Others }(U+M)
\end{aligned}
$$

Fig. 15. Contribution of each cause to each anomaly group

Attributing environmental actions to the triggering of anomalies requires a full understanding of their degradation paths, but they are made worse by defects in the materials or constructive errors. In fact even though the main causes were related to factors that are present throughout the service life of the system, such as environmental or external mechanical actions, the anomalies are generally indirectly related to design or application errors or materials selection.

The application errors group accounts for $16 \%$ of the overall causes in the sample, with special emphasis on cause C-E14 - Deficient overlapping of the finishing coat, attributed 41 times. This is partly due to the many times that anomaly A-P1 - Flatness deficiency was observed. Cause C-E15 - Deficient execution of flashings was attributed 9 times less than the previous one and 14 more than the next one. In fact it was found on site that various anomalies arose directly or indirectly from a deficient execution of the flashings, even though they were correctly designed. The most notable aspect of the incidence graphs is the simultaneously high values of some causes and very low values of others. Causes C-E5, C-E6 and C-E8 (respectively coincidence of the insulation plates' joints with discontinuities of the substrate, render between the insulation plates and mechanical anchors too tight) were never related to anomalies found on site. This is probably due to their occurring within the system, which can only be confirmed with destructive tests.

The C-C group of causes, design errors, only has five causes but they amount to a total of $14 \%$ of all the anomalies of the sample.

Figure 9 shows that cause C-C5 - Inadequate design of sills, flashings or on the ground-floor has the highest incidence in the group, and has been attributed (as direct or indirect cause) to 58 anomalies in the $146 \mathrm{fa}$ çades. As a matter of fact this error was associated several times with the development of regular water runoff paths that lead to efflorescence and the growth of microorganisms due to water accumulating on the wall. In other cases the non-existence of tail-ends led to various anomalies. The second most frequent cause in the design errors group was $\mathbf{C}-\mathbf{C 1}$ - Insufficient thickness of the base coat. Even though the appropriate thickness of each coat is stated in the European technical approval guideline for commercially available ETICS (ETAG 004 2000), lower values are often specified at the design stage, especially for the base coat, which leads to an overly thin coat $(1 \mathrm{~mm})$. Sometimes the thickness is omitted and application criteria are dictated by the appliers. The main consequence is the subsequent susceptibility of the system to impacts and perforations that expose the inner coats. In some cases the glass fibre grid was exposed instead of being embedded in the base coat, because the latter was too thin. It is also important for the designers to strengthen the reinforcement, especially in areas subjected to tensions that cause cracking, such as window openings and corners. Cause C-C2 - No reinforcement was related to 33 cases of cracking. Causes C-C3 - Deficient interface between the system and other elements and C-C4 No primary coat were the least frequent within the group, with a total of 10 and 11 attributions, respectively. Figure 15 shows that design and application causes (called "initial stages") prevailed over the other groups as causes of materials rupture anomalies and flatness anomalies. This reveals the sensitivity of the system to the planning and application tasks.

Figure 8 concerns the causes related to materials selection, with an overall contribution of $9 \%$ to the grand total of causes. Though it would be reasonable to regard these defects as design errors, by setting them apart it was possible to highlight problems specific to the materials. Causes C-M2 - Inadequate protection against micro- 
organisms of the finishing biocide (directly linked to the predominance of anomaly A-C5 - Biological growth in the sample) and C-M6 - Contaminated materials or ones having fabric defects stand out, which reveals the problem of incorrect use of materials, bearing in mind the characteristics required by the technical guidelines.

Finally the group of causes related to maintenance actions, mostly the lack of it and the consequences in terms of the development of existing anomalies and the emergence of new ones, accounts for $11 \%$ of all the causes in the sample. Containing only three causes, this group (and the environmental and external mechanical actions groups) clearly show the need for a correct maintenance plan, which must include the periodic inspection and diagnosis of the system, to solve the problems that arise in-service and control the degradation rate of the system.

Figure 14 shows that $39 \%$ of the anomalies in ETICS can be prevented by proper design, application and choice of materials, especially the materials rupture anomalies and the façade flatness anomalies. It is also concluded that implementing a plan of periodic inspections and maintenance helps to prevent early degradation from environmental and external mechanical actions during the service life, with special emphasis on the control of colour changes.

\subsection{Incidence observed of the diagnosis methods}

Figure 16 shows the number of times each test was recommended, with a grand total of 662 diagnosis methods for the 146 façades, and Figure 17 gives the incidence of each method relative to the 476 anomalies. There are more tests than there are anomalies since all except anomaly A-C4 - Graffiti, to which no specific method was assigned, could need the coupling of various in situ tests for a complete diagnosis.

Among the diagnosis methods recommended, D-T1 Infrared thermography and D-E1 - Contact moisture meter are important because they are associated with the diagnosis of various anomalies and the evaluation of their causes and are therefore the most useful on site, especially when used together (also because they are nondestructive). In fact they are recommended 159 and 155 times, respectively, in both cases more than the number of façades inspected (146). This proves how useful they are to help diagnose more than one anomaly or check on their severity, with an additional advantage of the contact moisture meter in terms of costs.

Since $10 \%$ of the anomalies concern oriented cracking and an extra $2 \%$ non-oriented cracking, it is natural that the recommendations of the alternative methods to measure the width of cracks, D-S1 - Crack comparator and D-S2 - Crack detection microscope, make 12\% of the total. Diagnosis method D-S2 is recommended in only 7 of the 58 cases of cracking ( $12 \%$ of those cases). In other words in only $12 \%$ of the cracking anomalies was it considered necessary to resort to the millimetre accuracy of the crack detection microscope instead of the crack comparator (D-S1). The method D-S3 - Crack meter, which can be used to monitor the stability of the cracks, had a similar usage frequency.

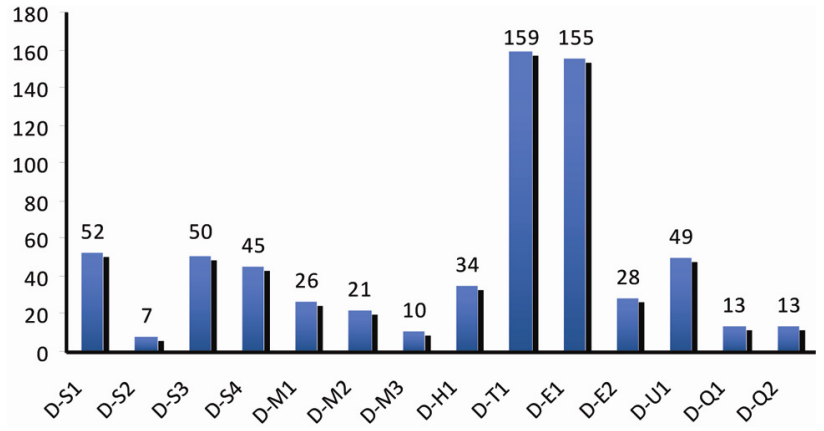

Fig. 16. Recommended diagnosis methods within the sample

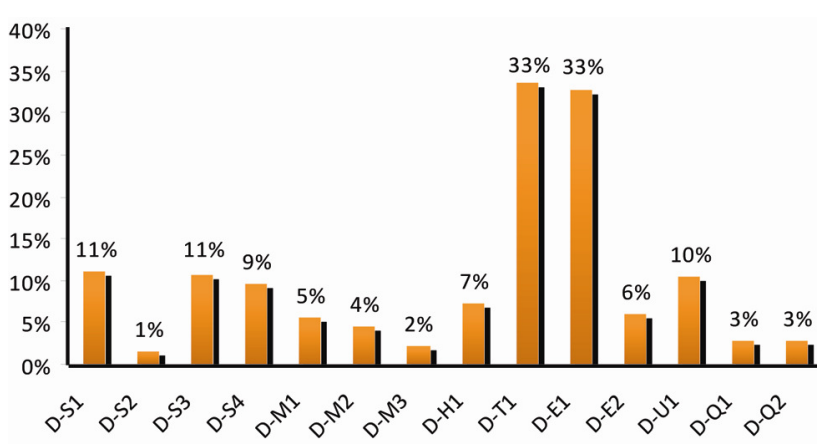

Fig. 17. Contribution of each method to the anomalies diagnosed

Also a part of the sensorial perception diagnosis methods group, probing (D-S4) is only recommended in $9 \%$ of cases, mostly because of the destructive nature of the method. Even though this is one of the most efficient ways to evaluate ETICS, enabling the origin of the error to be checked (application and/or design), the use of probing is only recommended when it is considered essential to the complete diagnosis of an anomaly.

Mechanical tests (D-M) showed frequencies between $2 \%$ and $5 \%$. Recommending these tests on site aimed at evaluating the characteristics of the base coat in terms of the use of certified materials and deformability, which are paramount in case of swelling, adherence loss and evaluation of the base coat thickness or before applying a reinforcement grid when the system is particularly susceptible to shocks.

The Karsten tube test (D-H1), a liquid water permeability test, is recommended for $7 \%$ of the anomalies identified, since it is directly linked to some causes of anomalies, namely $\mathbf{C - A 4}$ - Absorption and capillarity damp and C-H8 - Splattering at the bottom of the walls. The incidence of these causes in the sample was $10.9 \%$ for $\mathbf{C}-\mathbf{A} 4$ and $1.1 \%$ for $\mathbf{C}-\mathbf{H 8}$, which explains why in most cases the Karsten tube test was considered the most suitable diagnosis method. Alternatively or complementarily (depending on what is to be analysed) method D-E2 - Needles moisture meter is used to measure the moisture within the system and was recommended for $6 \%$ of the anomalies in the sample.

The chemical methods, D-Q1 - Colorimetric stripes and D-Q2 - Field kit, for statistical purposes were always recommended simultaneously to evaluate salts, and therefore the same number of times. One test is not pre- 
ferred over the other because both can be performed and the choice made between them later, in terms of salts evaluation, rather than on site. In comparative terms DQ1 are faster and cheaper but they are usually a preliminary test (with wider detection ranges). D-Q2 provides more accurate results but a spectrophotometer is needed and so it is costlier.

Additionally the mechanical action tests (D-M1 Sphere impact test - martinet baronnie, D-M2 - Perforation test (perfotest) and D-M3 - Pull-off test) were considered useful to diagnosing $2 \%$ to $5 \%$ of the anomalies observed. These values may be low because of their destructive nature, which makes them less likely to be chosen. However, in various situations these tests were considered indispensable, particularly to evaluate the characteristics of the materials used (e.g. A-M1 and A-M2), the adherence of the coats of the system and their tensile strength (A-M3) and the application of the system.

The diagnosis method D-U1 - Ultrasonic pulse velocity meter was recommended for $10 \%$ of the anomalies, $8 \%$ of which were associated with anomaly A-P1 - Flatness deficiency and its main cause C-E14 - Deficient overlapping of the finishing coat, and the remaining $2 \%$ to other cases where the results were considered relevant, i.e. the identification of defects, voids or changes to the internal coats of the system.

Even though the tests are used to diagnose various anomalies there is a clear pattern in the relationship between some factors and the recommended method. In other words, each test can be strongly linked to one of the objectives of the diagnosis.

Exemplifying this concept is the finding that method D-S3 - Crack meter is directly related to crack monitoring and that the causes linked to water leakages within the system are related to methods D-H1 - Karsten tube test or D-E2 - Needles moisture meter, and the corresponding groups of anomalies are somehow linked to these diagnosis methods. Therefore data on the relationship between each diagnosis technique recommended and the various anomaly groups were collected and analysed.

A strong relationship was found between the diagnosis methods groups D-S - Sensorial perception tests and D-M - Mechanical action tests and the materials rupture anomalies, and between the group of hydrodynamic methods (D-H1 - Karsten tube test) and the colour/aesthetic anomalies, which is justified by their relation to the causes associated with these anomalies. The methods D-E2 - Needles moisture meter and D-U1 Ultrasonic pulse velocity equipment are essentially related to the diagnosis of flatness anomalies (A-P). More specifically, the first one relates to swellings (A-P4 and A-P5) and the second one to flatness deficiencies (A-P1) and joints between plates being visible (A-P3).

It is thus concluded that there is a direct relationship between diagnosis methods and anomalies or groups of anomalies. Knowing this relationship facilitates the recommendation of these methods during the inspection.

\subsection{Incidence of the repair techniques}

Figure 18 shows that $43 \%$ of the repair techniques prescribed belong to the group of surface techniques (TR-A1 and TR-A2). They can be seen as maintenance and are directly related to the colour/aesthetic anomalies that represent around half of all the anomalies detected. On the other hand, the repair techniques concerning deeper interventions make up $24 \%$ of the universe, coinciding with the $24 \%$ of the materials rupture anomalies group, even though some of the techniques are prescribed for other anomalies, i.e. those concerning flatness deficiencies.

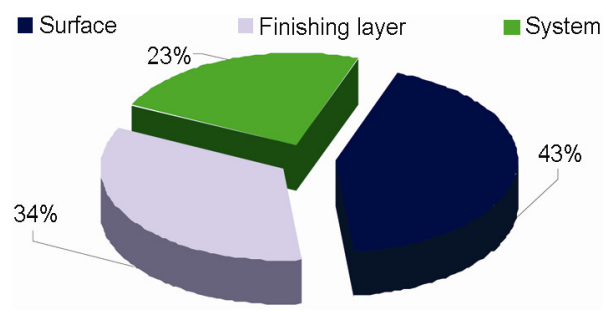

Fig. 18. Contribution of each repair technique group to the grand total of techniques prescribed

Figure 18 also shows that the technique TR-A1 Cleaning was the most often recommended because of the large number of colour/aesthetic anomalies, in particular leakage and biological growth. This has to do with the usually light colour of the system and lack of periodic maintenance as well as with the incorrect handling of singularities in the walls, such as sill drip edges and parapet capping, which allow biological organisms and other stains to build up on the façade.

Technique TR-A2 - Application of surface protection had quite a high incidence since it is generally implemented with cleaning.

Technique TR-B2 - Partial/whole replacement of the finishing coat was the second most often recommended since it remedies several anomalies at the level of the finishing, viz., surface gaps and irregularities and even flatness deficiencies.

Technique TR-C5 - Correction of geometrical constructive features is one of the most relevant techniques. Runoff marks (A-C2) mostly result from the careless handling of some singularities on the façade. The correction of these problems may require the application/replacement of drip edges, flashings and other constructive details, which eliminate or prevent the occurrence of this anomaly.

Technique TR-B3 - Application of a new finishing on top of the existing coat/paint layer is another of the most often recommended. This is partly due to its versatility at repairing anomalies. It tends to be recommended in situations of extreme soiling, when cleaning by itself is not enough, or when there are surface colour changes.

Technique TR-B1 - Filling/clogging of cracks is the best option in a great number of oriented cracking cases. For non-oriented cracking (mapped), which usually occurs in the finishing and is of considerable extent, technique TR-B2 would be preferable. 
The partial/whole replacement of the system (TR-C6) appears with a non-negligible incidence, in circumstances when surface repair would not be sufficient and deeper intervention is required.

Technique TR-C2 - Filling of material gaps/perforations, however, did not fulfil the initial expectations, even though $9 \%$ of the anomalies detected were material gaps. Because of the mechanical fragility of the system more damage caused by impacts and perforations was expected, even though some gaps between materials had already been repaired (usually incorrectly) leading to anomaly A-P2 - Surface irregularities.

Techniques TR-C1 - Protection of protruding edges and TR-C3 - Joint repair show lower incidence because they are intended for more specific repairs. TR-C1 targets the correction of damage to protruding edges, either cracks or material gaps. Furthermore, and even though it covers various methods of repairing joints, TR-C3 was suggested as a solution for anomalies other than cracking near expansion joints. This technique was considered when the ETICS needed to be separated from other construction elements or when the joints between plates were visible, where there was a possibility of the insulation material becoming dimensionally unstable and the creation of an expansion joint could solve the problem.

Finally technique TR-C4 - Application of new adhesive material and/or mechanical anchors is relatively rare compared with the other techniques, with only 9 recommendations. This low incidence is due to the specific nature of the technique, which is used only in situations of loss of adherence of the system or swelling of the plates. In the only situation of partial loss of adherence of the system replacement of that area was recommended. Therefore TR-C4 was recommended only to solve problems of swelling of the plates.

\subsection{Relationship between repair techniques and anomalies}

Based on the data collected during the inspection campaign the frequencies of each repair technique were correlated with the various anomalies, as seen in Figure 19. The techniques aimed at repairing the anomalies and/or eliminating their causes.

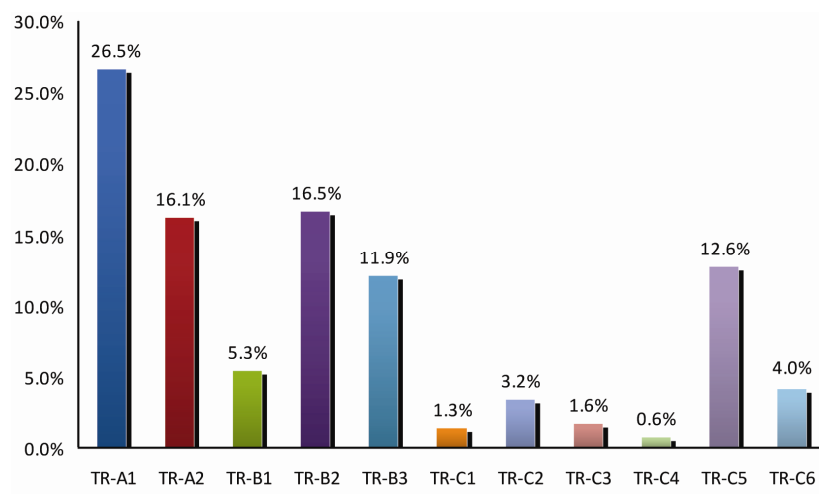

Fig. 19. Incidence of the repair techniques prescribed

Oriented cracking (A-M1.1) was mostly solved by technique TR-B1 - Filling/clogging of cracks, and in some cases by partial/whole replacement of the system (TR-C6), usually when plates coincided with the profiles' joints. Non-oriented cracking (A-M1.2) was usually handled by technique TR-B2 - Partial/whole replacement of the finishing coat, given the superficial nature of the anomaly, though techniques TR-C6 or TR-C5 - Correction of geometrical constructive features were occasionally chosen if the anomaly was considerably extensive or resulted from an incorrectly fitted construction element (Fig. 20).

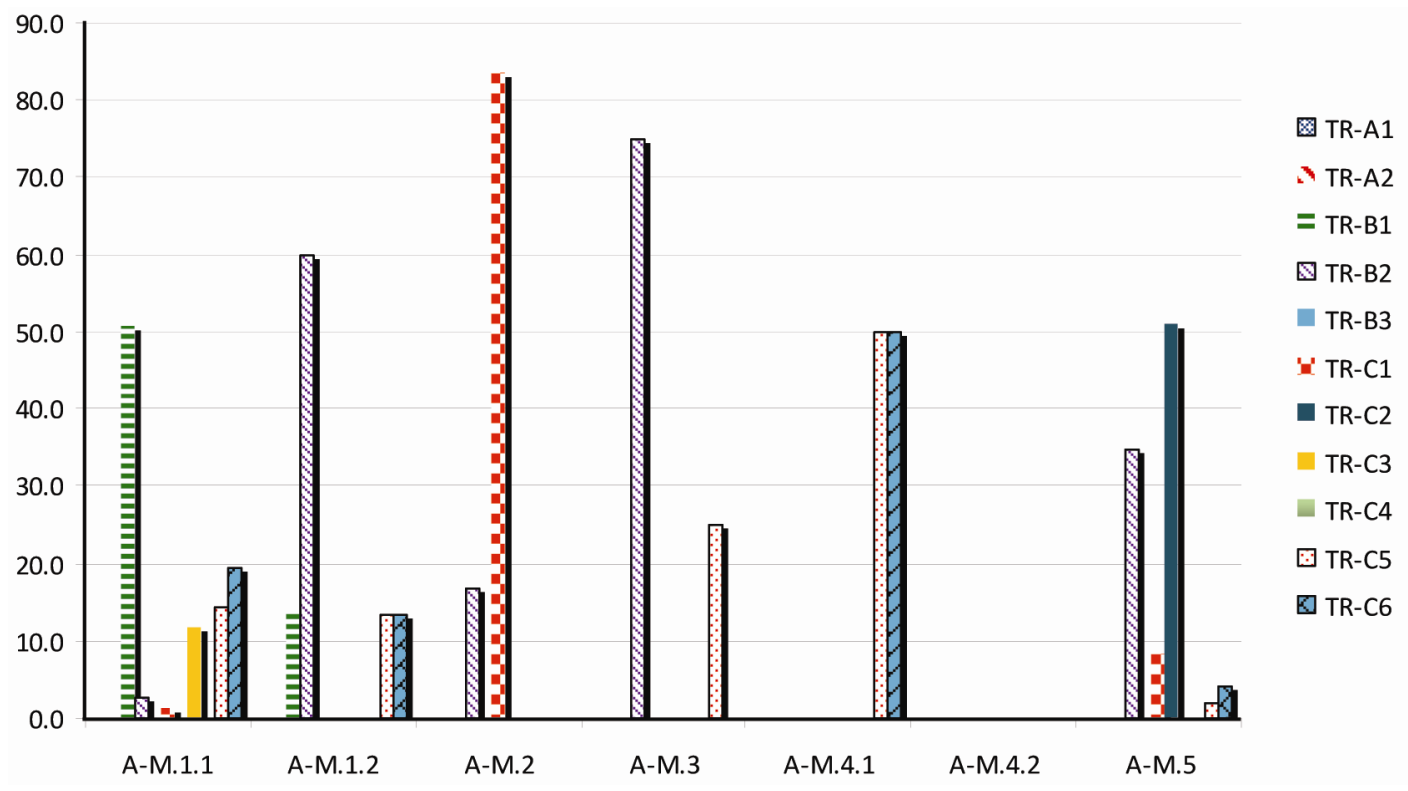

Fig. 20. Incidence of each technique to repair materials rupture anomalies 


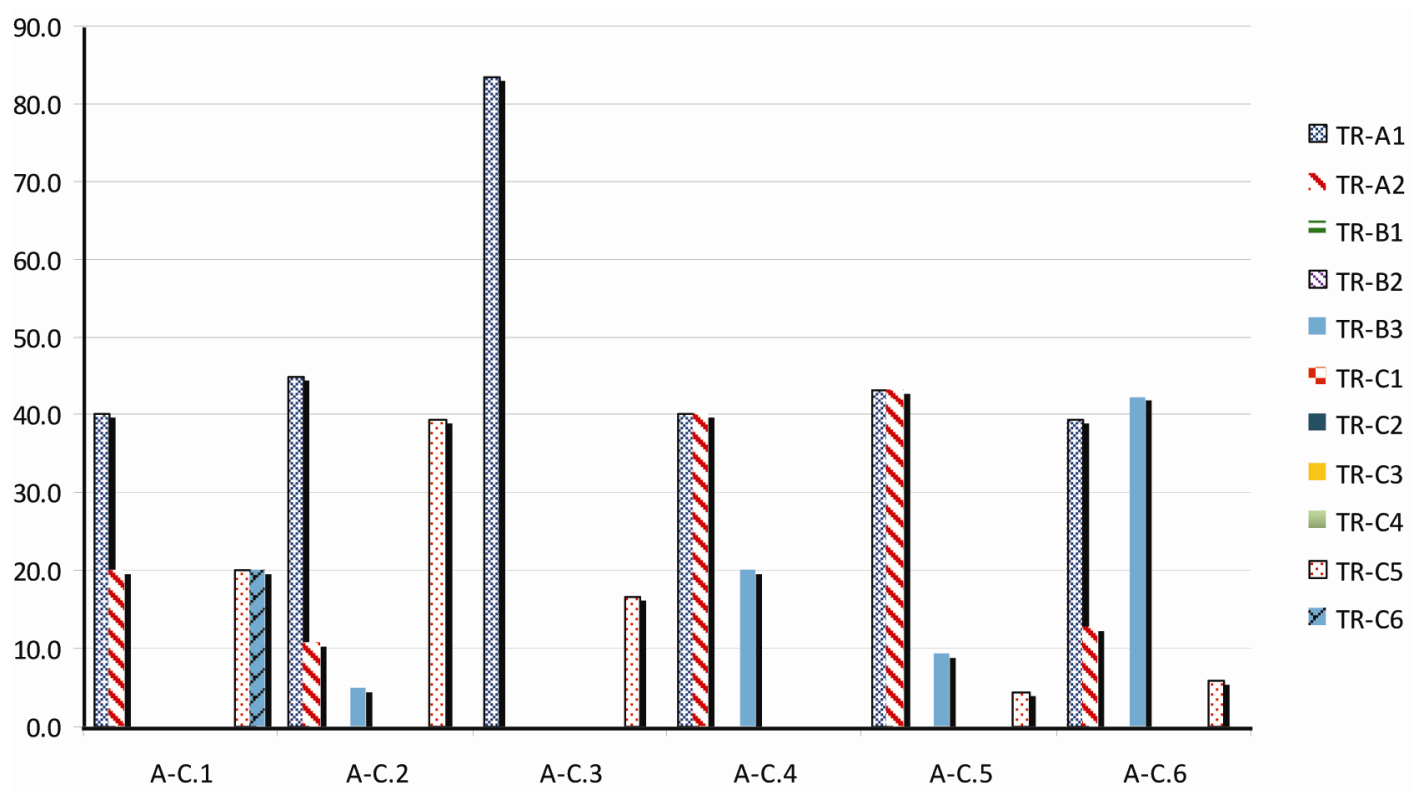

Fig. 21. Incidence of each technique to repair colour/aesthetic anomalies

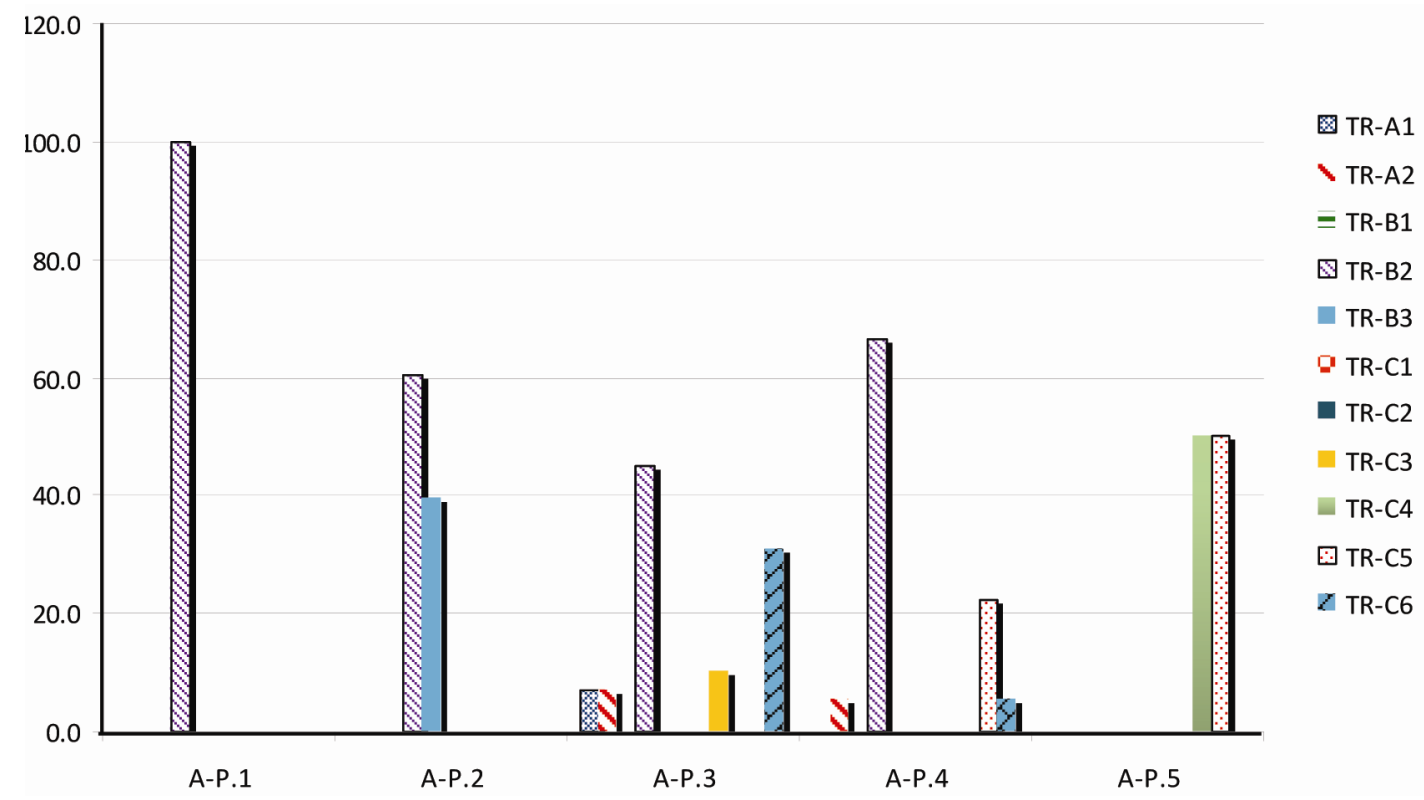

Fig. 22. Incidence of each technique to repair flatness anomalies

The best technique for the deterioration of the covering of reinforcement cantilevers (A-M2) was TR-C1 Protection of protruding edges, as expected, given its specificity. For slight deterioration of the finishing technique TR-B2 - Partial/whole replacement of the finishing coat was recommended. The same technique was prescribed $75 \%$ of the times to remedy anomaly A-M.3 - Detachment of the finishing even though it was sometimes complemented by technique TR-C 5 - Correction of geometrical constructive features, since replacing the finishing solves the anomaly and correcting the tail-end elements eliminates the possible cause (Fig. 20).

To finish the materials rupture anomalies, the only case of partial loss of adherence of the system (A-M4.1) was solved by partial/whole replacement of the system (TR-C6), complemented with technique TR-C5, in this case resorting to back wrapping and replacement/installation of the bottom profile. The material gaps (A-M5) observed were mostly handled using technique TR-C2 - Filling of material gaps/perforations, whenever the perforation gap reached the insulation plate or the substrate (51\% of cases). For more superficial gaps that only reached the reinforced mortar but did not damage the grid, partial/whole replacement of the finishing coat (TR-B2) proved to be sufficient. Technique TR-C1 was prescribed locally to treat protruding edges when the location of the material gap near the edges justified the treatment of that area and the installation of corner profiles was not considered (Fig. 20).

In the colour/aesthetic anomalies group there is a high incidence of cleaning (TR-A1) and in most cases application of surface protection (TR-A2). Anomalies 
A-C1 - Efflorescence and A-C3 - Corrosion stains were rare in the sample analysed, representing less than $2 \%$ in total. With the exception of a single case of efflorescence, where no deeper intervention was deemed necessary, both anomalies were solved by surface cleaning (TR-A1), in both cases over a small area, and correction of geometrical constructive features (TR-C5) (Fig. 21).

Runoff marks (A-C2) and biological growth (A-C5) represent $61 \%$ of the colour/aesthetic anomalies and $30 \%$ of all anomalies. In the first case, cleaning (TR-A1) was most often prescribed to eliminate the marks. But to eliminate the causes, correction of geometrical constructive features (TR-C5) became fundamental. As for the manifestation of micro-organisms on the system's surface, cleaning (TR-A1) and complementary application of surface protection (TR-A2) were the techniques chosen to eliminate the anomaly and prevent its recurrence. In both cases, more severe problems were repaired by painting the wall, thus justifying the incidence of technique TR-B3 in both cases (Fig. 21).

Graffiti (A-C4) strongly affects the aesthetics of a façade and is not always easy to remove. Consequently, combining cleaning (TR-A1) and the application of an anti-graffiti barrier (TR-A2), repainting the wall (TR-B3) was deemed necessary in $50 \%$ of the situations when this anomaly was detected. Depending on the characteristics, damp and dirt stains, surface decolouration, and other problems within anomaly A-C. 6 - Other colour changes, were solved through simple cleaning (TR-A1). In the case of dirt stains (e.g. due to atmospheric pollution), cleaning plus the application of water repellent (TR-A2) was the technique used for runoff marks, and the application of a new finishing/painting (TR-B3) for other colour changes, especially those caused by incorrect surface repairs (Fig. 21).

Flatness anomalies are mostly due to incorrect characteristics or application of the finishing coat or damage to it. Apart from swelling of the insulation plates (A-P5) which implies another level of intervention, the first four anomalies of the group require an intervention to the finishing coat, usually by partial/whole replacement (TR-B2). In fact anomaly A-P1 - Flatness deficiency was dealt with solely by this technique, which was considered sufficient given the causes established. This anomaly has a sizeable incidence (8\%) and in almost all instances its origin was a deficient overlapping of the finishing coat (86\%) during the system's application. Depending on the height of the scaffolding when the system was installed, it could have been applied in horizontal coats. The transition between a new coat and the previous one must ensure the greatest possible homogeneity at the level of overlapping of the finishing coat. Surface irregularities (A-P2) come from uneven texture of the finishing coat, from incorrect interventions or from small superficial material gaps. The replacement of the finishing coat (TR-B2) and the application of a new finishing on top of the existing coat (TR-B3) were the preferred techniques to rectify this anomaly (Fig. 22).

Joints between plates visible (A-P3) is caused mostly by incoherencies in terms of the base coat or the di- mensional stability of the insulation plates. Deficiencies of the base coat are solved by the partial/whole replacement of the finishing coat (TR-B2). However, the dimensional instability of the plates requires the creation of an expansion joint (TR-C3) to allow movement of the system, or, as a last resort, its replacement (TR-C6). Swelling of the finishing coat (A-P4) necessarily requires its replacement. The correction of geometrical constructive features (TR-C5) was prescribed to eliminate the causes of this anomaly, in this case essentially by capping the parapets, areas where water can infiltrate the system, thereby boosting this and other types of anomalies (Fig. 22).

As with the previous anomaly, so swelling of the insulation plates (A.P5) may also derive from seepages into the system, which justifies the frequent prescription of technique TR-C5 to eliminate its causes. But to deal with the anomaly itself, which generally results from deficient anchoring of the plates to the substrate as well as faulty preparation of the latter, technique TR-C4 - Application of new adhesive material and/or mechanical anchors seems like the natural choice (Fig. 22).

\section{Conclusion}

There are pathology, diagnosis and repair systems for a variety of construction elements, but in the literature survey performed none was found concerning the evaluation of ETICS.

That was the main objective of this research, aiming at monitoring the performance of ETICS on walls. Furthermore it is expected that some of the difficulties inherent to the need for specialized labour may be eased by creating a plain, concise and innovative document.

Both the system itself and all the assumptions made in its creation (Amaro et al. 2013) were validated and calibrated after field work and statistical post-treatment of the data collected on 146 façades where ETICS had been applied. These statistics concern the performance of the system and made it possible to perfect the process of evaluating and intervening in the system.

The following conclusions can be drawn:

- The commonest anomalies of ETICS in walls (approximately once every two cases) are biological growth, other colour changes and runoff marks, all included in the colour/aesthetic anomalies group; flatness and materials rupture anomalies come second and third respectively (approximately a quarter of the occurrences each);

- The most frequent causes of the anomalies (approximately once every six anomalies) are dirt build-up (dust), surface condensation damp and rain action, and the most prolific groups of causes are external mechanical actions and environmental actions;

- Around two out of five of the anomalies in ETICS can be prevented by proper design, application and choice of materials, which shows the importance of these stages in the service life of ETICS;

- Infrared thermography and contact moisture measurements account each for around one third of all 
diagnosis methods recommended in the event of an anomaly being found in ETICS;

- The most frequent repair techniques prescribed are those that act on the surface of the system (cleaning and application of surface protection), followed by those that act on the finishing coat (with emphasis on the partial/whole replacement) and only about one fifth of the times does the system core need to be intervened upon (with emphasis on the correction of geometrical constructive features).

\section{References}

Amaro, B.; Saraiva, D.; de Brito, J. de; Flores-Colen, I. 2013. Inspection and diagnosis system of ETICS in walls, Construction and Building Materials 47: 1257-1267. http://dx.doi.org/10.1016/j.conbuildmat.2013.06.024

Barreira, E.; Freitas, V. P. 2008. Defacement of ETICS cladding due to hygrothermal behaviour, in Proc. of the $11^{\text {th }}$ International Conference on Durability of Building Materials and Components, Istanbul, Turkey, paper T 24.

Barreira, E.; Delgado, J. M. P. Q.; Ramos, N. M. M.; Freitas, V. P. 2013. Exterior condensations on facades: numerical simulation of the undercooling phenomenon, Journal of Building Performance Simulation 6(5): 337-345. http://dx.doi.org/10.1080/19401493.2011.560685

Daniotti, B.; Paolini, R. 2008. Evolution of degradation and decay in performance of ETICS, in Proc. of the $11^{\text {th }}$ International Conference on Durability of Building Materials and Components, Istanbul, Turkey, paper T 42.

De Brito, J. 2009. Sistemas de inspecção e diagnóstico em edifícios [Inspection and diagnosis systems in buildings], in Proc. of the $3^{\text {rd }}$ National Meeting on Pathology and Rehabilitation of Buildings, Porto, Portugal, 13-23.

Duarte, C. 2011. A Europa das argamassas e dos ETICS. Tendências, perspectivas e oportunidades [The Europe of mortars and ETICS. Trends, perspectives and opportunities], in Proc. of the IX SBTA - Brazilian Symposium on Mortars Technology, Belo Horizonte, Brazil, 7-16.

ETAG 004 2000. Guideline for European technical approval of external thermal insulation composite systems with rendering, Brussels, Belgium.

Fernandes, C.; de Brito J. 2012. Soluções para integração arquitectónica do sistema ETICS em reabilitação [Solutions for architectural integration of the ETICS system in rehabilitation], in $4^{\text {th }}$ Congress on Construction and ETICS, Coimbra, Portugal, 39/2012.

Flores-Colen, I.; de Brito, J.; Freitas, V. P. 2008. Stains in facades' rendering - diagnosis and maintenance technique classification inspection, Construction and Building Materials 22(3): 211-221.

http://dx.doi.org/10.1016/j.conbuildmat.2006.08.023

Freitas, V. P. 2002. Isolamento térmico de fachadas pelo exterior - reboco delgado armado sobre poliestireno expandido - ETICS [Thin reinforced render over expanded polystyrene - ETICS], in Report HT 191A/02, MAXIT Construction and Renovation Technologies, Ltd, Porto, Portugal.

Künzel, H. M. 1998. Effect of interior and exterior insulation on the hygrothermal behavior of exposed walls, Materials and Structures 31(2): 99-103. http://dx.doi.org/10.1007/BF02486471

Künzel, H.; Künzel, H. M.; Sedlbauer, K. 2006. Long term performance of external thermal insulation systems
(ETICS), Acta Scientiarum Polonorum Architectura 5(1): 11-24.

Neto, N.; de Brito, J. 2011. Inspection and defect diagnosis system for natural stone cladding (NSC), Journal of Materials in Civil Engineering 23(10): 1433-1443.

http://dx.doi.org/10.1061/(ASCE)MT.1943-5533.0000314

Neto, N.; de Brito, J. 2012. Validation of an inspection and diagnosis system for anomalies in natural stone cladding (NSC), Construction and Building Materials 30(1): 224236. http://dx.doi.org/10.1016/j.conbuildmat.2011.12.032

Pereira, A.; Palha, F.; de Brito, J.; Silvestre, J. D. 2011. Inspection and diagnosis system for gypsum plasters in partition walls and ceilings, Construction and Building Materials 25(4): 2146-2156. http://dx.doi.org/10.1016/j.conbuildmat.2010.11.015

Sá, G.; Sá, J.; de Brito, J., Amaro, B. 2013. Inspection and diagnosis system for rendered walls, Journal of Civil Engineering (approved for publication).

Silva, J. A. R. M.; Falorca, J. 2009. A model plan for buildings maintenance with application in the performance analysis of a composite facade cover, Construction and Building Materials 23(10): 3248-3257. http://dx.doi.org/10.1016/j.conbuildmat.2009.05.008

Silvestre, J. D.; de Brito, J. 2009. Ceramic tiling inspection system, Construction and Building Materials 23(2): 653668. http://dx.doi.org/10.1016/j.conbuildmat.2008.02.007

Silvestre, J. D.; de Brito, J. 2011. Ceramic tiling in building facades: inspection and pathological characterization using an expert system, Construction and Building Materials 25(4): 1560-1571. http://dx.doi.org/10.1016/j.conbuildmat.2010.09.039

Stazi, F.; di Perna, C.; Munafò, P. 2009. Durability of 20-yearold external insulation and assessment of various types of retrofitting to meet new energy regulations, Energy and Buildings 41(7): 721-731.

http://dx.doi.org/10.1016/j.enbuild.2009.02.008

\section{LIST OF ACRONYMS}

A-M - Materials rupture anomalies

A-M1.1 - Oriented cracking

A-M1.2 - Non-oriented cracking

A-M2 - Deterioration of the covering of reinforcement cantilevers

A-M3 - Detachment of the finishing coat

A-M4.1 - Partial loss of adherence

A-M4.2 - Loss of adherence of the whole system

A-M5 - Material gap

A-C $\quad-$ Colour/Aesthetic anomalies

A-C1 - Efflorescence

A-C2 - Runoff marks

A-C3 - Corrosion stains

A-C4 - Graffiti

A-C5 - Biological growth (lichens, fungi, algae, plants)

A-C6 - Other colour changes

A-P - Flatness anomalies

A-P1 - Flatness deficiency

A-P2 - Surface irregularities

A-P3 - Joints between plates visible

A-P4 - Swelling of the finishing coat

A-P5 - Swelling of the insulation plates

C-M - Materials selection

C-M1 - Insufficient dimensional stability of the insulation material

C-M2 - Inadequate protection against micro-organisms of the finishing biocide 


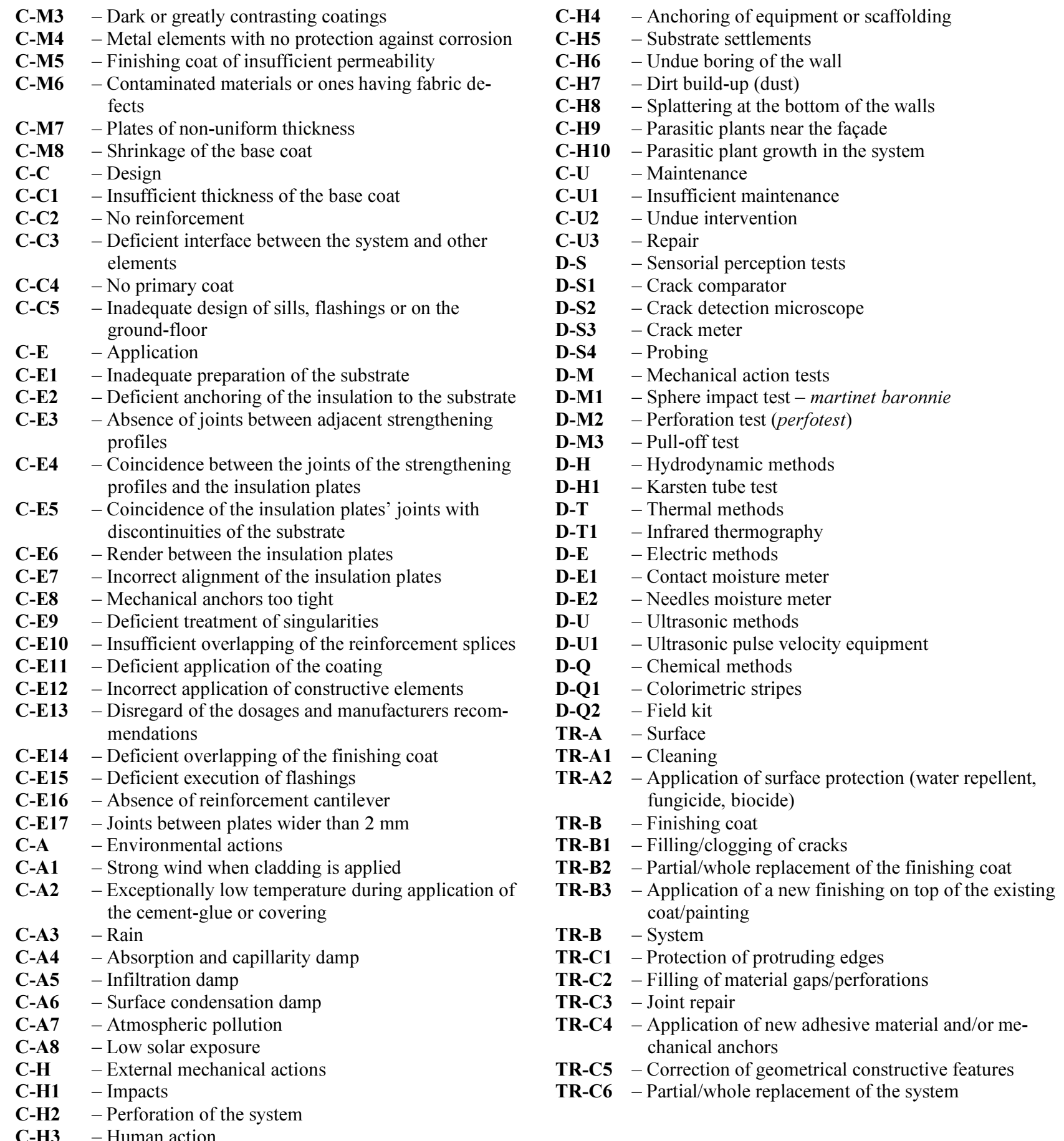

Bárbara AMARO holds a Master's degree in Civil Engineering from Instituto Superior Técnico, Technical University of Lisbon, Portugal. Her research interests include the life cycle of construction elements.

Diogo SARAIVA holds a Master's degree in Civil Engineering from Instituto Superior Técnico, Technical University of Lisbon, Portugal. His research interests include the life cycle of construction elements.

Jorge de BRITO is a Full Professor at Instituto Superior Técnico, Technical University of Lisbon, Portugal. He is a member of CIB W80, W86 and W115. His research interests include the performance, pathology, in situ testing, diagnosis, maintenance, rehabilitation and service life prediction of buildings and construction elements and sustainable construction.

Inês FLORES-COLEN is an Assistant Professor at Instituto Superior Técnico, Technical University of Lisbon, Portugal. She is a member of CIB W86 and W70. Her research interests include the performance, pathology, in situ testing, diagnosis, maintenance, rehabilitation and service life prediction of buildings and construction elements. 